\title{
Identidade judaica: considerações psicológicas acerca da dimensão religiosa
}

\author{
Jewish identity: psychological \\ considerations about religious dimension
}

\author{
Solange EPELBOIM $\mathbf{M}^{1,2,3}$
}

\begin{abstract}
Resumo
O estudo compreendeu considerações psicológicas acerca de aspectos religiosos presentes no delineamento da identidade judaica. Foram elaborados comentários relativos à condição de ser israelita, aos pontos de aproximação entre psicologia e religião, à teoria referente ao desenvolvimento religioso e, por fim, aos dez mandamentos existentes na Torá. A dimensão religiosa é aqui compreendida sendo composta por aspectos racionais, emocionais e atitudinais direcionados à presença de um poder divino e capaz de desempenhar funções espirituais e sociais que convidariam o ser humano a refletir sobre questões intrapessoais, interpessoais e transcendentais. A identidade judaica pareceu reunir características singulares e compartilhadas entre israelitas, uma vez que cada pessoa pode revelar senso, experiência, inquietação e grau de enraizamento religiosos distintos.
\end{abstract}

Palavras-chave: experiências religiosas; identidade social; judaísmo; religião e psicologia.

\begin{abstract}
This study encloses the psychological considerations about religious aspects in Jewish identity delineation. Commentaries has been developed about the condition of being an Israeli, the closest aspects between psychology and religion, the religious development theory, and Torah's. Ten Commandments The religious dimension is composed by rational, emotional and attitudinal aspects oriented to the presence of a divine power, that is able to play spiritual and social functions. These functions may drive people to reflect about personal, interpersonal and transcendental concerns. Jewish identity has included Israelis' singular and public features, as each person can reveal a particular religious sense, experience, uneasiness.
\end{abstract}

Key words: religious experiences; identity social; Judaism; religion and psychology.

1 Doutoranda, Programa de Pós-Graduação em Psicologia Social, Universidade do Estado do Rio de Janeiro. Rio de Janeiro, RJ, Brasil.

2 Professora Doutora, Curso de Graduação em Psicologia e Curso de Pós-Graduação em Psicologia Clínica e Psicologia Social, Universidade Estácio de Sá. R. Eduardo Luiz Gomes, 134, centro, 24020-340, Niterói, RJ, Brasil. E-mail: <epelboim@ig.com.br>.

3 Professora Doutora, Universidade Católica de Petrópolis. Petrópolis, RJ, Brasil.

Agradecimentos: ao professor Dr. Helmuth Krüger, orientador que, com excelência, dedicação e seriedade, contribui para minha formação como docente e pesquisadora na área da Psicologia. 
Em momento anterior, Epelboim (1997) examinou os processos de formação, manutenção e possível transformação da identidade judaica. Tal investigação compreendeu considerações teóricas e proposta empírica. No que tange àquela parte, foram estabelecidas discussões acerca da constituição do ser social, etapa na qual foi concedido destaque aos conceitos identidade e socialização. No que se refere à questão de identidades psicossociais, foram desenvolvidos comentários sobre a definição desse termo à luz das ciências Sociais, da Psicologia, da Psicologia Social, e a partir da noção psicossociológica de crença.

Quanto à última proposta, Krüger (1995a) defendeu que o conceito de identidade poderia ser definido como a consciência que toda pessoa tem sobre si mesma e sobre características capazes de diferenciá-la dos outros. Esse nível de consciência permitiria ao homem formular crenças sobre sua unidade, a qual expressaria sua organização e coerência no que tange à sua personalidade e conduta. Krüger (1995b) ainda salientou que a identidade estaria relacionada à apercepção do sujeito; reuniria em sua configuração diferentes dimensões; seria constituída por crenças descritivas e avaliativas, as quais confeririam à identidade aspecto dinâmico; e contribuiria para o desenvolvimento da personalidade e conduta do indivíduo. Quanto ao conceito de crença psicossociológica, Krüger (1995c) concedeu destaque às características referentes ao nível de consciência, objeto das crenças, modo de apresentação, dimensão temporal, condição necessária ou contingente, caráter descritivo ou prescritivo, grau de consenso, nível de aceitação subjetiva e grau de compatibilidade.

Cabe mencionar que Epelboim (1997) compreendeu o conceito de identidade psicossocial a partir da noção psicossociológica de crença, noção que aponta para a significativa participação do processo de socialização na construção do sujeito como ser social. Quanto à socialização, tal processo foi entendido como universal, contínuo, dinâmico e vinculado à adoção de papéis sociais. Por fim, faz-se necessário comentar que foram estabelecidas considerações, na parte teórica da dissertação ora comentada (Epelboim, 1997), acerca de três dimensões que pareciam ocupar posições relevantes no delineamento da identidade judaica: aspectos religiosos, étnicos e políticos. É oportuno salientar que o presente artigo tem por objetivo elaborar considerações psicológicas acerca da participação dos aspectos religiosos na configuração da identidade judaica.

Quanto à parte empírica do trabalho, houve aplicação de questionário (sobre a definição da condição de ser judeu) em oitenta pessoas israelitas residentes na cidade do Rio de Janeiro. O instrumento ora mencionado compreendeu três partes - instruções aos participantes, dados pessoais e nove perguntas abertas. Ainda no que se refere ao questionário, optou-se pela sua não apresentação no atual artigo, uma vez que a exposição do instrumento não viria ao encontro do objetivo do presente estudo. Desse modo, julga-se apropriado apenas mencionar que a pergunta número 1 era relativa à configuração da identidade judaica, enquanto as questões número 2 , 4 e 6 examinavam, respectivamente, os processos de formação, manutenção e modificação da identidade em foco. As perguntas número 3 e 5 também abordavam os processos de construção e sustentação, mas convidavam o participante a se aproximar do plano real, e não ideal, de ações. $O$ item 7 se referia às mudanças e só era respondido se o participante concordasse com a questão número 6. As perguntas número 8 e 9 buscavam examinar, respectivamente, aspectos étnicos e políticos envolvidos no delineamento em foco.

As respostas dos participantes foram examinadas a partir da análise de conteúdo e indicaram a predominância de fatores religiosos, etnoculturais, educacionais, sociocomunitários e emocionais, os quais estabeleciam relações entre si. Nesse sentido, aspectos religiosos apontavam para a observância dos mandamentos divinos. Entretanto, tais aspectos se revelam presentes nas atividades diárias e também nas datas comemorativas, momentos que compreendem não só a realização de preces, mas a narração de histórias que explicam o significado das festas, o preparo de comidas típicas, o canto de músicas específicas, a reunião familiar, a visita à sinagoga, entre outros fatores que parecem demonstrar a forte vinculação entre aspectos religiosos, etnoculturais, educacionais e sociocomunitários. Assim, a transmissão e a manutenção de 
tradições religiosas parecem intimamente vinculadas a heranças culturais, implicando tal conexão a percepção, por parte da pessoa israelita, do pertencimento a um grupo etnicamente diferente dos demais.

Quanto ao âmbito educacional, a condição de ser israelita pode ser transmitida ao longo das gerações através de modos formais (escolas israelitas e sinagogas), e informais (grupos de jovens, de adultos, clubes, participação em entidades assistenciais sociocomunitárias, tradições familiares, entre outras alternativas). Entretanto, cabe salientar que há discussões no judaísmo sobre a possibilidade da pessoa se definir como israelita, pois, enquanto ortodoxos relacionam tal condição ao nascer de ventre judeu ou à conversão religiosa, vertentes não ortodoxas concedem destaque à prevalência de aspectos socioculturais judaicos no desenvolvimento do sujeito.

Já a esfera sociocomunitária envolve o compromisso do indivíduo em prestar assistência e estabelecer relações qualitativamente satisfatórias com outras pessoas. Embora seja possível perceber - predomínio desse compromisso entre componentes do grupo ora examinado, faz-se necessário salientar que o desenvolvimento de relações éticas com membros de outros conjuntos também é estimulado. Maiores informações acerca desse tópico serão fornecidas posteriormente neste artigo, mais especificamente na análise da dimensão religiosa da identidade judaica à luz dos dez mandamentos existentes na Torá. Por fim, aspectos emocionais foram assinalados, uma vez que, entre as esferas do pensar, sentir e agir, os participantes definiram a identidade judaica, sobretudo, como associada ao sentimento de ser israelita.

\section{Psicologia e religião}

O exame de aspectos religiosos presentes no delineamento da condição de ser israelita parece nos convidar à análise do campo referente à psicologia da religião. Essa área, segundo Rosa (1992), compreenderia questionamentos acerca dos métodos e princípios psicológicos que poderiam ser utilizados na abordagem científica do comportamento religioso - entendendo-se por comportamento religioso a atitude voltada a fatores divinos ou sobrenaturais concebidos a partir da fé manifestada por pessoas.

Quanto ao critério científico, é apropriado incluir as observações apresentadas por Schilling (2001a) ao longo da definição do verbete psicologia da religião. Nesse sentido, caberia a esse domínio o exame de estruturas psíquicas da consciência religiosa, estudo que poderia envolver aplicação de diferentes metodologias, como de natureza experimental, crítica e fenomenológico-compreensiva. De acordo com o autor acima citado, a pesquisa experimental prevaleceu a partir de 1900 e contribuiu para a construção de uma crítica exagerada à religião e às categorias usadas no âmbito teológico. Após 1930 passaram a ser encontradas propostas de compreender a religiosidade inerente à condição humana, a qual revelaria sentimentos religiosos e não seria completamente desvendada por esforços experimentais.

A referida abordagem hermenêutica vem ao encontro da definição exposta por Schilling (2001b) no que tange ao verbete religião, uma vez que essa foi caracterizada como união pela fé, vínculo que se desenvolveria na vivência do sagrado e provocaria ações responsáveis nas esferas do culto e da ética. Desse modo, não caberia à psicologia da religião defender a veracidade ou falsidade de qualquer crença religiosa, mas investigar os fenômenos psicológicos que viessem a se relacionar com as experiências religiosas. Acredita-se que tais fenômenos se manifestariam através de comportamentos que, por serem direcionados a um poder divino ou sobrenatural, seriam denominados de religiosos.

A partir dessas considerações, faz-se necessário esclarecer que a identidade religiosa é definida neste trabalho como sendo desenvolvida a partir de crenças que o indivíduo exibe com relação à presença de um poder divino ou sobrenatural. Tais crenças fornecem recursos para que o sujeito compreenda a criação do universo e dele próprio. Entretanto, a identidade religiosa parece não ser composta apenas por crenças, mas também por valores, atitudes, princípios éticos e morais que visam orientar as ações humanas. Tais componentes apresentam como base aspectos racionais, emocionais e atitudinais que devem ser 
mantidos em permanente equilíbrio e revelam a condição do homem como ser biológico, psicológico, sociocultural e espiritual. Esse comentário aponta para a necessidade de estabelecer diferenças entre as noções de crença psicossociológica e religiosa, pois, enquanto no primeiro caso objetiva-se o equilíbrio entre razão, emoção e ação, no segundo parece prevalecer o aspecto emocional. Tal prioridade contribui para que emoções sejam as principais sustentadoras da fé, fator que dificulta muitas vezes a reflexão crítica do material apreendido e defendido por adeptos de diferentes religiões, uma vez que o questionamento dos princípios adotados pode ser interpretado, pelos seguidores da crença religiosa, como desrespeito da pessoa frente à religião, comprometendo sua fé e, até mesmo, podendo culminar no seu afastamento.

De acordo com Penna (1999), a fé estaria relacionada à esfera do sagrado, que seria conhecida pela revelação e não por critérios racionais. Já a ciência envolveria o uso de processos cognitivos que permitiriam o exame da verificabilidade ou refutação das conjecturas estabelecidas. Essa diferenciação parece apontar para a análise dos possíveis encontros e desencontros entre ciência e religião. Penna (1999) comentou que, enquanto desencontros foram ressaltados por defensores de uma perspectiva positivista, encontros entre os referidos domínios foram investigados por pesquisadores que privilegiaram o estudo de comportamentos religiosos a partir de diferentes recursos metodológicos, sem, contudo, elegerem o julgamento quanto à veracidade ou não da esfera transcendente como tarefa a ser por eles executada.

Quanto aos papéis desempenhados pela identidade religiosa, Epelboim (1997) considera que essa dimensão tenha como propósito cumprir funções de ordem espiritual e social. Na esfera espiritual a identidade ora discutida parece fornecer suporte emocional aos homens, subsídio capaz de minimizar o mal-estar psicológico que surge quando os mesmos se deparam com questões frente às quais não têm respostas, como, por exemplo, a origem da vida, seu sentido, o que há após a morte e qual a dimensão do livre arbítrio do sujeito. Quanto à esfera social, a dimensão em questão garante ao homem a adoção de crenças, valores e ações que the permitem participar de um grupo social específico. Além desse fator, a identidade religiosa parece trazer em sua configuração o valor da comunhão, isto é, do encontro entre o homem e Deus, do homem com seus semelhantes e do homem consigo próprio, compromisso que parece apontar para a definição de religião como religação. Esse aspecto demonstra a importância da sociabilidade, do contato repleto de sinceridade, responsabilidade, respeito e consciência entre as pessoas, comunhão que precisa ser estimulada e exercitada não só entre os adeptos de determinada religião, devendo ultrapassar os contornos intragrupos a fim de evitar o etnocentrismo e possibilitar satisfatória integração social. Tal condição vem ao encontro da observação feita por Farias (2003), no que tange ao termo religião, já que o referido autor, além de ter indicado a definição apoiada na palavra religare, apontou também a vinculação com a noção de relegere, o que definiu como reler com cuidado, ser prudente na observância dos deveres religiosos, aspecto que parece apontar, sobretudo, para a presença de compromissos éticos e morais no exercício da socialização.

\section{Desenvolvimento religioso}

Amatuzzi (1999a; 1999b; 2000a; 2000b; 2001) apresentou uma proposta mais complexa no que se refere ao desenvolvimento da dimensão religiosa, proposta que se revelou pela construção de uma teoria que compreende etapas. Amatuzzi (1998) concebeu a psicologia da religião como área destinada ao estudo da experiência religiosa, a qual expressaria a relação que se estabelece entre o homem e a esfera transcendente ao longo das situações cotidianas vividas pelo mesmo. Ao utilizar o termo experiência, o autor concedeu destaque a aspectos racionais, emocionais e comportamentais provenientes do contato autêntico do sujeito com a realidade. A experiência religiosa revelaria, então, a consciência que o indivíduo possui acerca da relação que estabelece com o transcendente, relação que aponta para a condição de encontro com algo exterior ao sujeito, fator que supera os limites intrapessoais da inquietação religiosa. Ao enfatizar o aspecto relacional, Amatuzzi (1996; 1998) defendeu a importância das 
contribuições oferecidas por Martin Buber, contribuições como a crença oriunda do encontro vivo; a manifestação religiosa que ocorre ao longo de situações comuns da vida diária de cada indivíduo, e de situações especiais relativas à coletividade; a relação com o transcendente no contexto real da vida humana; o poder criativo e transformador da experiência religiosa; a exigência da reciprocidade, isto é, o envolvimento e compromisso do sujeito com o outro, encontro que atende à voz divina através de ações; e a dinâmica dialógica.

Quanto às etapas existentes no desenvolvimento religioso, Amatuzzi (2000a) advertiu que elas envolveriam a articulação entre questões psicológicas, experiências religiosas significativas e formas de tradição religiosa. Desse modo, o referido autor comentou que o senso religioso buscaria responder ao sentido último da vida humana, senso que poderia ser expresso por diferentes formas religiosas que poderiam revelar níveis ou graus distintos de enraizamento religioso. A vivência religiosa do sujeito envolveria momentos que permitiriam a apresentação e o fortalecimento da fé religiosa. Amatuzzi (1999a) definiu fé como confiança básica no transcendente, que contribuiria para o crescimento humano.

Amatuzzi (1999b; 2001) afirmou que o desenvolvimento religioso envolveria etapas; a primeira delas ocorreria no primeiro ano de vida do bebê, momento em que seria conferida importância à confiança básica que o bebê poderia manifestar frente aos seus cuidadores e, gradativamente, frente a outras pessoas significativas. Nesse período não seria possível identificar a presença de experiências, formas ou sistemas religiosos no bebê.

A criança, a partir de um ano até seis ou sete anos de idade, seria capaz de estabelecer novas formas de interação com o mundo, principalmente através do uso da linguagem. A prática religiosa apresentada pela criança demonstraria apenas a repetição da forma adotada pela família, quando aspectos simbólicos passariam a exercer papel importante. A partir dessa fase, até o menino ou menina completar onze ou doze anos, haveria maior compreensão acerca do sentido das histórias religiosas relatadas na família. Na adolescência, período que para o autor ora abordado se estenderia dos onze ou doze anos até dezoito ou dezenove anos, haveria questionamento sobre a crença religiosa da família, gradativo afastamento dos pais e eleição de grupos de amigos. De dezoito a dezenove anos até vinte e quatro ou vinte e cinco anos, o jovem estabeleceria relações marcadas por maior intimidade, o que poderia também refletir uma maior disponibilidade para experiência religiosa. Depois dessa idade, até 35 ou 40 anos, o adulto se encontraria na fase de gerar e cuidar de seus filhos, transmitindo suas crenças religiosas. Após esse período, até sessenta ou sessenta e cinco anos, o adulto maduro expressaria uma forma religiosa mais pessoal, congruente com seus valores, e não mais direcionada, sobretudo, aos regulamentos institucionais. O idoso manifestaria sua fé através da confiança no entregar-se ao transcendente. Faz-se necessário salientar que Amatuzzi (2000b) introduziu mais uma fase em seu modelo, fase intitulada proximidade da morte, que ocorreria a partir dos oitenta anos e implicaria a aceitação equilibrada da morte.

Considerando-se essas observações, é oportuno refletir sobre questões específicas existentes no judaísmo, questões que parecem importantes, sobretudo, como marcos para iniciação e manutenção da condição de ser judeu. Nesse sentido, poder-se-ia pensar no papel desempenhado pelo brit-milá (circuncisão); pela prática de dar o nome dos filhos, em hebraico, durante o britmilá (no caso de meninos) ou em leitura da Torá na sinagoga, geralmente no shabat seguinte ao nascimento (no caso de meninas); pela educação religiosa; pela comemoração das festas religiosas; pela observância dos mandamentos divinos; e pelo bar e bat-mitzvá (maioridade religiosa, quando o menino - aos treze anos - e a menina - aos doze anos - são considerados responsáveis por suas atitudes, de acordo com a religião).

Entretanto, enquanto o brit-milá e a cerimônia do nome podem ser vinculados à primeira fase apontada por Amatuzzi (1999b; 2000a; 2000b), momento em que o bebê é apresentado à tradição religiosa familiar, a comemoração das festas e o cumprimento dos mandamentos divinos na vida diária familiar contribuem, através de aspectos educacionais informais, para gradativa compreensão da experiência religiosa. Supõe-se que, com a entrada em escola 
israelita - o que cumpriria o papel da educação formal, o menino e a menina possam entender melhor as histórias contidas na filiação religiosa em questão. A cerimônia de bar ou bat-mitzvá pode garantir a vinculação à religião em momento muitas vezes repleto de crises, em função do questionamento, por parte do adolescente, acerca das crenças, valores e atitudes mantidas pela família. Apesar das interrogações existentes, acredita-se que a comemoração da maioridade religiosa implique uma maior aproximação frente ao grupo familiar. Logo, supõe-se que as questões propostas pelo adolescente permitam maior compreensão acerca da religião adotada. Nessa fase, observa-se também a participação do adolescente em grupos de jovens, os quais apresentam orientação religiosa mais ou menos ortodoxa.

Nas etapas denominadas jovem e adulto, o sujeito se ocupa com a manutenção e transmissão de sua vivência religiosa aos seus descendentes, a fim de constituir seu lar à luz de específica tradição religiosa. Supõe-se que a exigência de endogamia represente uma estratégia que visa justamente garantir a sustentação e transmissão da religião. Embora o não atendimento dessa exigência possa dificultar a manutenção da condição de ser judeu, acredita-se que a mesma não impeça tal exercício, uma vez que, conforme já mencionado, os não ortodoxos acreditam que aspectos educacionais, e não necessariamente vinculados à descendência, garantam a condição da pessoa ser considerada israelita. O compromisso com a sustentação e transmissão da vivência religiosa, ao longo de diferentes gerações, parece atender ao quinto mandamento existente na Torá, isto é, respeitar os pais. Esse mandamento indica a relevância da harmônica constituição familiar, que engloba a família de origem, assim como a de descendentes.

Quanto à etapa adulto maduro, não se verifica na Torá a defesa da não observância dos mandamentos divinos, qualquer que seja a idade ou mesmo forma de expressão religiosa apresentada pelo sujeito. Quanto a esse fator, embora ortodoxos e não ortodoxos revelem diferentes critérios para o cumprimento dos mandamentos, eles se aproximam ao não abandonarem sua observância. Ainda no que tange ao adulto maduro, a expressão religiosa pessoal é sempre estimulada no judaísmo, ainda que em concordância com os regulamentos institucionais, já que tais fatores não são apresentados como contraditórios, mas vinculados, uma vez que a religião judaica defende o cumprimento das leis divinas de forma refletida e responsável, a partir do estudo da Torá.

\section{A condição de ser judeu}

\section{Considerações psicológicas}

Por se acreditar que a Torá represente o principal sustentáculo da religião judaica, tal obra foi escolhida em sua forma escrita para ser analisada. Desse modo, serão fornecidos neste momento breves comentários sobre a Torá, obra também conhecida como Pentateuco, uma vez que reúne os cinco livros que transcrevem as leis que foram dadas por Deus a Moisés. A Torá, em sua forma escrita, apresenta a história da criação do universo e da humanidade, descrevendo a vida dos patriarcas, a origem, o desenvolvimento e a permanência do Povo de Israel e, ainda, as leis que devem ser obedecidas pelos judeus. Quanto a essa parte legislativa, a Toráapresenta 613 mandamentos ou mitzvót (plural de mitzvah) que devem ser cumpridos por todos os filhos de Israel, mandamentos que compreendem 248 preceitos positivos (o que se deve fazer) e 365 preceitos negativos (o que não se deve fazer). Entretanto, faz-se necessário informar que muitos mandamentos se referem a práticas que não estão mais em vigor, como, por exemplo, as que discutiam os sacrifícios oferecidos no Templo. Dentre os inúmeros preceitos presentes na Torá, optou-se por se analisar os dez mandamentos que foram dados por Deus a Moisés no Monte Sinai, na tentativa de investigar os princípios que com eles se identificam.

Com base no trecho da Torá acima referido, observa-se que o primeiro mandamento se refere à existência de um Deus único, poderoso e bondoso que salvou os filhos de Israel da escravidão, proporcionando-Ihes uma vida melhor e que deve ser o único Deus louvado e amado por eles. Tal mandamento parece explicitar de modo bastante sucinto um princípio fundamental no judaísmo - o 
monoteísmo. O monoteísmo expressa a crença na unidade de Deus. Tal unidade, segundo Asheri (1995), é especial, pois apresenta Deus como um único que não se assemelha a qualquer outro ser existente, já que este pode ser dividido em partes, enquanto aquele é absolutamente indivisível, representando a menor unidade possível de existir.

Entretanto, ao defender Deus como único, revela-se também a não-existência de qualquer outro ente que a ele se iguale e demonstra-se ainda suas características enquanto um, completo, perfeito, justo, poderoso, forte, miraculoso, misericordioso, entre tantas outras. Assim, sua unidade também aponta para a condição de ser a maior unidade possível, uma vez que não há qualquer limite capaz de restringir a existência e a vontade divina. Ao apresentar a existência de um só Deus, o judaísmo entende que o universo foi criado e se mantém unificado pela dependência que possui frente ao poder e à vontade divina.

O segundo mandamento expressa a proibição de se exercer qualquer tipo de idolatria. Assim, o amor dos judeus para com Deus não deve ser expresso através da adoração de ídolos, mas sim através do estudo da Torá e do cumprimento de seus mandamentos. O estudo da Torá não consiste em uma tarefa puramente intelectual vinculada às leis divinas, mas sim em uma proposta que contribui para o crescimento interior ou espiritual do indivíduo, envolvendo o desenvolvimento de aspectos emocionais, racionais e atitudinais. Ao compreender os preceitos da Torá, o homem é capaz de cumprir os mandamentos conscientemente, ou seja, por meio de condutas e ações moralmente desejáveis e responsáveis, e não pela obediência cega, mecânica e desmedida.

O terceiro mandamento revela a proibição de se jurar em vão pelo nome de Deus, o que demonstra mais uma vez o poder divino, estabelecendo uma distinção entre a existência do universo e de Deus. Defende-se, assim, a transcendência de Deus e sua santidade.

O quarto mandamento expressa a santidade do sétimo dia da semana. Desse modo, cabe a todo israelita guardar o shabat, isto é, não exercer qualquer tipo de trabalho desde o pôr-do-sol de sexta-feira até o pôr-do-sol de sábado. O cumprimento desse mandamento parece proporcionar uma distinção entre o mundo físico e o mundo espiritual. Nesse dia, estimula-se a realização de atividades que visam desenvolver aspectos religiosos, espirituais ou interiores do homem, como a prece e a reflexão. O shabat parece representar, então, um tempo destinado à interiorização ou à apercepção do sujeito, movimentos que parecem contribuir para o estabelecimento de um encontro mais satisfatório do indivíduo para com ele mesmo, para com os outros e, sobretudo, para com Deus. De acordo com Heschel (2000), o shabat marca a distinção entre o mundo do tempo e o mundo do espaço, uma vez que nesse dia é concedido destaque ao ser e não ao ter, ao compartilhar e não ao controlar, ao processo de criação e não ao produto de criações, apontando para sua vinculação à dimensão temporal.

O quinto mandamento demonstra a importância que a família possui na religião judaica. Convida-se o homem não só a estabelecer um relacionamento adequado com os familiares dos quais é descendente, mas também a constituir uma família onde prevaleça tal condição de harmonia.

O sexto, sétimo, oitavo, nono e décimo mandamentos, diferentemente dos cinco anteriores, se destinam prioritariamente às relações que o homem estabelece com os outros homens. Desse modo, parecem orientar as interações humanas de forma a ocorrerem ética e moralmente. Enquanto esses mandamentos se caracterizam por envolver aspectos sociais, os quatro primeiros parecem estar mais vinculados a aspectos religiosos ou espirituais. 0 quinto mandamento, ao conferir importância ao respeito que os filhos devem ter para com seus pais, revela tanto um aspecto religioso de enaltecer a vida em família e a harmonia presente no lar, como também ressalta aspectos sociais, ao tratar da qualidade das relações que se estabelecem entre o homem e seus familiares.

\section{Considerações Finais}

A elaboração de considerações psicológicas acerca de aspectos religiosos presentes na configuração da identidade judaica permitiu a apresentação de comentários relativos à condição de ser israelita, aos pontos de aproximação entre psicologia e religião, à teoria referente ao 
desenvolvimento religioso e, por fim, aos dez mandamentos existentes na Torá.

Quanto aos últimos, embora seja observada uma maior ênfase a fatores religiosos em alguns mandamentos e, em outros, a aspectos sociais, não se pode fazer essa separação de modo rigoroso, uma vez que a Torá não explicita tal distinção. A Torá pretende que seus mandamentos, que compõem sua parte legislativa, compreendam tanto aspectos religiosos (que podem ser entendidos como direcionados a questões intrapessoais que contribuem para o estabelecimento de relações entre o homem e Deus), como também aspectos sociais (que podem ser vinculados a questões de cunho interpessoal). O entrelaçamento entre aspectos religiosos e sociais garante a emergência de princípios que irão nortear o contato do homem com ele mesmo, com outros sujeitos e com Deus, isto é, princípios que irão convidar o ser humano a constantemente refletir sobre questões intra-pessoais, interpessoais e transcendentais.

O plano interpessoal não se limita aos contornos da comunidade judaica, mas se estende ao estabelecimento de relações intergrupais, o que parece apontar para a estreita vinculação entre as dimensões religiosa e étnica na configuração da identidade judaica. Conforme mencionado anteriormente, Epelboim (1997) acredita que, sobretudo, fatores religiosos, etnoculturais, educacionais, sociocomunitários e emocionais participem do delineamento em questão.

De acordo com Epelboim (1997), a compreensão da identidade judaica a partir da noção psicossociológica de crença implica a apercepção, por parte do sujeito, principalmente das dimensões religiosa e étnica. Essas dimensões são compostas por crenças descritivas e avaliativas, ideológicas e utópicas, as quais podem revelar elevados níveis de consciência, aceitação subjetiva e congruência. Tais níveis, gradativamente mais elevados, parecem acompanhar as etapas relativas ao desenvolvimento religioso propostas por Amatuzzi (1999a; 1999b; 2000a; 2000b; 2001). Sugere-se ainda que esses níveis indiquem consenso entre adeptos de uma mesma filiação religiosa (no que tange à definição da religião adotada) e a existência de senso, experiência, vivência, inquietação e grau de enraizamento religiosos distintos por parte dos mesmos.

\section{Referências}

Amatuzzi, M. M. (1996). A Experiência religiosa: uma leitura de Martin Buber. Estudos de Psicologia, 13 (3), 63-70.

Amatuzzi, M. M. (1998). Experiência religiosa: busca de uma definição. Estudos de Psicologia, 15 (1), 49-65.

Amatuzzi, M. M. (1999a). Religião e sentido de vida: um estudo teórico. Temas em Psicologia da SBP, 7(2), 183-190.

Amatuzzi, M. M. (1999b). Desenvolvimento psicológico e desenvolvimento religioso: uma hipótese descritiva. In: M. Massimi \& M. Mahfoud (Orgs.). Diante do mistério (pp.123140). São Paulo: Edições Loyola.

Amatuzzi, M. M. (2000a). O Desenvolvimento religioso: uma hipótese psicológica. Estudos de Psicologia, 17 (1), 15-30.

Amatuzzi, M. M. (2000b). O Desenvolvimento religioso: análise de depoimentos. Estudos de Psicologia, 17 (3), 43-66.

Amatuzzi, M. M. (2001). Esboço de teoria do desenvolvimento religioso. In G. J. Paiva (Org.). Entre necessidade e desejo: diálogos da psicologia com a religião (pp.25-51). São Paulo: Edições Loyola.

Asheri, M. (1995). O Judaísmo vivo: as tradições e as leis dos judeus praticantes. Rio de Janeiro: Imago.

Epelboim, S. (1997). Identidade judaica: formação, manutenção e possível modificação. Dissertação nãopublicada, Instituto de Psicologia, Universidade Federal do Rio de Janeiro.

Farias, F. R. (2003). O Saber científico e a existência de Deus. Trabalho apresentado no Fórum de Debates das Faculdades Integradas Maria Thereza - FAMATh, Niterói, RJ.

Heschel, A. J. (2000). O Schabat: seu significado para o homem moderno. São Paulo: Editora Perspectiva.

Krüger, H. (1995a). Identidade étnica, identidade transcultural e transnacionalismo. Monografias Psicológicas, 11 (1), 21-43.

Krüger, H. (1995b). Notas sobre a identidade teutobrasileira. Monografias Psicológicas, 11 (1), 7-20.

Krüger, H. (1995c). Psicologia das crenças: perspectivas teóricas. Rio de Janeiro: Departamento de Psicologia Social e Institucional, Universidade do Estado do Rio de Janeiro.

Penna, A. G. (1999). Em busca de Deus: introdução à Filosofia da religião. Rio de Janeiro: Imago.

Rosa, M. (1992). Psicologia da religião. Rio de Janeiro: Junta de Educação Religiosa e Publicações da Convenção Batista Brasileira.

Schilling, W. (2001a). Psicologia da religião. In F. Dorsch, H. Häcker \& K. H. Stapf (Orgs.). Dicionário de Psicologia Dorsch (pp.746-748). Rio de Janeiro: Vozes.

Schilling, W. (2001b). Religião. In F. Dorsch, H. Häcker \& K. H. Stapf (Orgs.). Dicionário de Psicologia Dorsch (pp.826-827). Rio de Janeiro: Vozes.

Recebido em:15/4/2004

Versão final reapresentada em: 25/5/2005

Aprovado em: 14/9/2005 